\title{
Effects of testosterone on intraocular pressure, thickness of retinal nerve fiber layer, ganglion cell complex, macula and on ocular blood flow in female-to-male transgender persons
}

\section{Oksan Alpogan ( $D$ oksanalpogan68@gmail.com )}

Haydarpasa Training and Research Hospital: Istanbul Haydarpasa Numune Egitim ve Arastirma Hastanesi

\section{Emin Erhan Donmez}

Haydarpasa Training and Research Hospital: Istanbul Haydarpasa Numune Egitim ve Arastirma Hastanesi

\section{Ayşe Özlem Balık}

Haydarpasa Training and Research Hospital: Istanbul Haydarpasa Numune Egitim ve Arastirma Hastanesi

\section{Fisun Vural}

Haydarpasa Training and Research Hospital: Istanbul Haydarpasa Numune Egitim ve Arastirma Hastanesi

\section{Gizem Kaplan}

Haydarpasa Training and Research Hospital: Istanbul Haydarpasa Numune Egitim ve Arastirma Hastanesi

\section{Research Article}

Keywords: Testosterone, transgender, retinal nerve fiber layer, macular thickness, ganglion cell complex, ocular blood flow

Posted Date: February 23rd, 2021

DOl: https://doi.org/10.21203/rs.3.rs-219665/v1

License: (c) (1) This work is licensed under a Creative Commons Attribution 4.0 International License. Read Full License

Version of Record: A version of this preprint was published at International Ophthalmology on July 8th, 2021. See the published version at https://doi.org/10.1007/s10792-021-01921-y. 


\section{Abstract}

\section{Purpose}

To compare the effects of testosterone on intraocular pressure (IOP), retinal nerve fiber layer thickness (RNFL), ganglion cell complex (GCC), macular thickness (MT), and ocular blood flow between female-tomale transgender (FMT) persons who use testosterone and healthy women and healthy men.

Method

The study included 39 eyes of 20 FMT(group 1), 40 eyes of 20 healthy women (group 2), and 42 eyes of 21 healthy men (group 3). In all subjects, RNFL, GCC, MT were measured by optical coherence tomography (OCT). Ocular blood flow was measured by Colour Doppler Ultrasonography in all subjects.

Results

IOP levels in FMT were significantly higher than men $(p=0.02)$. Para superior (Sup), Para inferior (Inf) and Peri nasal (Nas) thickness in FMT were significantly higher than the group $2(p=0.02, p=0.03, p=$ 0.01). Peri Sup thickness in FMT was significantly higher than group $3(p=0.01)$. Peri Inf thickness in FMT was significantly higher than group 2 and $3(p=0.03, p=0.002)$. Mean thickness of RNFL Inf in FMT was significantly higher than the group 2 and $3(p=0.03, p=0.03)$. Avg GCC, Inf GCC in FMT were significantly higher than group $2(p=0.02, p=0.005)$. In correlation test, systole/diastole ratio(S/D) in Ophthalmic artery $(O A)(r=0.504, p=0.028)$ and Inf RNLF thickness $(r=0.485, p=0.035)$ were positively correlated with the serum levels of testosterone in FMT.

Conclusions

We found that the use of supraphysiologic testosterone dose increased IOP and the thickness of macula, RNFL and GCC in FMT. Serum testosterone level was positively correlated with S/D ratio in the OA.

\section{Introduction}

Gonadal hormones play an important role in the function of other systems such as cardiovascular and bone, as well as the reproductive system [1]. Although it is produced in both genders, its amount varies according to gender and age. These hormones are also produced by other organs besides the gonads [2].

The fact that gonadal hormone receptors have been shown in the eye has increased the studies on the effects of hormones on the eye. Sex steroid hormone receptor (SSHR) has been shown throughout the eye such as conjunctiva, lacrimal gland, meibomian gland, cornea, iris, ciliary body, lens, and retina [3]. Estrogen receptor $a$, estrogen receptor $\beta$, progesterone receptor, and androgen receptor mRNAs have been identified in all these locations [4]. In addition, the synthesis of sex steroids in the retina and the presence of enzymes involved in the synthesis have been shown $[5,6]$. 
Different physiological and pathological features of eye diseases between the sexes draw attention to the effects of gonadal hormones. In many animal and clinical studies demonstrating the effects of estrogen, estrogen has been shown to reduce intraocular pressure, increase ocular blood flow, and exert neuroprotective effects on the optic nerve [7-11]. In a clinical study conducted with multifocal electroretinography ( $\mathrm{mERG}$ ), it is stated that neuroretinal function is better in women under 50 years of age compared to men, and this difference disappears after the age of 50 [12]. In a study revealing the effects of premenopausal and postmenopausal sex hormones, it is stated that testosterone works as an antagonist of estrogen, with the beneficial effect of estrogen on ocular hemodynamics. While estrogens have a vasodilator effect on retinal perfusion, testosterone and progesterone have the opposite effect [13].

Although the negative effects of testosterone on the cardiovascular system have been described, conflicting results have been reported in this regard [14]. It is possible that androgens have direct effects due to the presence of steroid receptors in the vascular endothelium [15]. In addition, testosterone increases the level of endothelin, a potent vasoconstrictor [16]. However, studies on the effects of testosterone on ocular blood flow and optic nerve are limited. These studies have focused on patients with Polycystic ovary syndrome (PCOS) with high androgen levels. High levels of nerve growth factor have been found in animal experiments in cases with PCOS with hyperandrogenism and high plasma luteinizing hormone (LH) concentration [17]. In a clinical study, an increase in retinal nerve fiber thickness (RNFL) was found in patients with PCOS and it was assumed that this increase was due to the effect of nerve growth factor [18]. The neuroprotective effect of testosterone on the nervous system has been demonstrated by regeneration and improvement in neurons and glia $[19,20]$. Additionally, it has been shown that testosterone has an effect on the increase in myelin sheath thickness and axonal caliber [21].

The transition from female-to-male gender include stages such as the use of supraphysiologic testosterone dose, mastectomy, and hysterectomy with bilateral salphingo-oophorectomy after psychological and physiological controls of cases with female genetics.

In this study, we aimed to evaluate the effects of testosterone on intraocular pressure (IOP), RNLF, ganglion cell complex (GCC), macular thickness (MT), and ocular blood flow in female-to-male transgender (FMT) persons. To the best of our knowledge, our research is the first study in the literature in terms of the group characteristics and parameters included.

\section{Method}

This prospective study was carried out in accordance with the standards of the Helsinki declaration and was approved by the Research Protocol and Ethics Committee of Haydarpasa Numune Training and Research Hospital (HNEAH-KAEK 2020/212).

\section{Study Design:}


The study group included 21 FMT cases (Group 1), 20 healthy women (Group 2) and 20 healthy men (Group 3).

Twenty-one cases between the ages of 18-40 who have been using testosterone for at least one year for conversion from female-to-male sex were included in the study. One of the cases was excluded due to the presence of keratoconus disease. One eye of one patient was excluded because of optic disc drusen. Thirty-nine eyes of 20 cases constituted Group 1. All cases had normal menstrual cycles before testosterone use and ovarian sizes were within normal limits. All the FMT cases were evaluated pior to hysterectomy and bilateral salphingo oopherectomy operation. All FMT cases had testesterone treatment at least one year. Four of 20 cases was using Nebido vial (Testosterone undecanoate, Bayer, Germany) $1000 \mathrm{mg} / 3$ months, 16 of them Sustanon (testosterone propionate $30 \mathrm{mg}$, testosterone phenylpropionate $60 \mathrm{mg}$, testosterone isocaproate $69 \mathrm{mg}$, testosterone decanoate $100 \mathrm{mg}$, Eczacıbaşı, Turkey) $250 \mathrm{mg} / \mathrm{month}$. Serum levels were measured for oestradiol and free testosterone in Group 1.

The control groups were formed with two separate groups matched with the study group by age. Forty eyes of 20 healthy women (Group 2) and 42 eyes of 21 healthy men (Group 3) were included in the control group. The control groups were selected from healthy volunteers in their reproductive ages. None of the patients in all groups had a systemic disease (endocrine diseases, hypertension, diabetes mellitus, collagen vascular disease, cardiovascular diseases) or a history of any ocular disease; and refractive errors were not greater than \pm 3 diopters as spherical equivalent. Visual acuity was above $8 / 10$ in all cases. None of the subjects in the control group received any hormone therapy and/or supplements and prior ovarian surgery. In the female control group, women with irregular menstrual cycles, oligoanovulatory cycles, clinical or laboratory findings of hyperandrogensim, hormononal medication, hyperprolactinemia, pregnancy and lactation were excluded from the study.

\section{Opthalmologic Evaluation}

A full ophthalmologic examination was performed on each patient which included medical history, corrected visual acuity, detailed fundus examination, Goldmann applanation tonometry, and central corneal thickness (CCT) measurement. Macular thickness (MT) (internal limiting membrane and retinal pigment epithelial layer), RNFL, ganglion cell complex (GCC) (retinal nerve fiber, ganglion cell, and inner plexiform layer), inner retinal layer (IRL) (retinal nerve fiber, ganglion cell, inner plexiform and inner nuclear layer), outer retinal layer ( $\mathrm{ORL}$ )(outer plexiform and outer nuclear layer) measurements were made with FD-OCT (RTVue-100, Optovue, Fremont, CA). Measurements with low signal strength $(<50)$, not focused on the fovea or optic disc center or artifacts were not evaluated. All opthalmologic examinations was performed by the same opthalmologist (OA).

A mapping of nine sectoral thickness subfields in three concentric circles of diameters 1, 3, and $6 \mathrm{~mm}$ was used to obtain MT measurements. Foveal, parafoveal, and perifoveal average (Avg), superior (Sup), temporal (Temp), inferior (Inf), and nasal (Nas) sectors were evaluated. In addition, IRL and ORL thickness of perifovea were measured. 
RNFL thickness was measured using 13 concentric ring scans 1.3 to $4.9 \mathrm{~mm}$ in diameter (587 to 965 different axial scans per ring) centered on the optic disc. The Avg, Sup, Temp, Inf, Nas RNFL measurements were evaluated.

The GCC was measured using the scan protocol "GCC." The GCC was measured with 1 horizontal line with a 7-mm scan length (467 axial scans per line, centered $1 \mathrm{~mm}$ temporal to the fovea, and with a scan time of $0.59 \mathrm{~s}$ ) and 15 vertical lines with a 7-mm scan length (400 axial scans per line, 0.5-mm interval between 2 lines, centered in the middle of the horizontal scan line). The Avg, Sup, and Inf GCC measurements were evaluated.

\section{The Color Doppler Evaluation}

After 15 minutes of resting, the patients lay down with their eyes closed, both eyes held straight. We used the linear probe with a frequency of range 4-15 MHz of Esaote, MyLab 9 eXP model ultrasonography (Genova, Italy). We obtained our images using the triplex method i.e. combination of 2D ultrasonography (two-dimensional real-time ultrasonography, 2D US), color-coded Doppler, and spectral Doppler method. All Doppler evalautions were performed by the same ultrasonographer (AÖB).

The measurement angle for all arteries was approximately $10^{\circ}-20^{\circ}$. Flow velocity parameters in the $\mathrm{OA}$, took at the intersection of the OA with the optic nerve $20-25 \mathrm{~mm}$ behind the eyeball in the nasal part of the orbit.

During an examination, we determined peak systolic velocity (PSV), end-diastolic volume (EDV) which are qualitative values, and resistance index $(\mathrm{RI})$, pulsatility index $(\mathrm{PI})$, and systole/diastole ratio(S/D) which are quantitative values.

One hundred twenty-one eyes of 61 patients were examined. The examination took approximately 10-15 minutes per eye. We calculated and documented mean values; after this obtained arterial doppler values of both eyes as were aforementioned.

\section{Statistical analysis}

The results are expressed as mean \pm standard deviation. Statistical analysis was performed using SPSS Version 22 (IBM SPSS, Turkey). Data distribution was analyzed. If data were normally distributed, then parametric statistical tests were used; otherwise, non-parametric tests were used.

The differences between all study groups in IOP, MT, RNFL, GCC measurements, and ocular blood flow parameters were determined by ANOVA test or Kruskal Wallis Test. A p-value $<0.05$ was considered as statistically significant.

The relationship between all parameters and serum levels of oestradiol and testosterone was determined by Pearson's correlation or the Spearman ranked correlation coefficients.

\section{Results}


Subject characteristics and mean values of IOP, cup/disc ratio, CCT, Body Mass Index (BMI), estrogen 2, and testosterone are shown in Table 1. The IOP levels in FMT were significantly higher than in men $(\mathrm{p}=$ 0.025). The cup/disc ratio in men was significantly higher than in Groups 1 and $2(p=0.000, p=0.002)$. The duration of testosterone use was minimum 17, maximum 60 months in FMT $(29.66 \pm 9.80)$.

Table 1

Subject characterics: age, Body Mass Index (BMI), intraocular pressure (IOP), cup/disc ratio (C/D), central corneal thickness (CCT), estrogen2, testosterone, testosterone usage time (mean \pm SD)

\begin{tabular}{|c|c|c|c|c|c|}
\hline & $\begin{array}{l}\text { Group } 1 \\
(n=20)\end{array}$ & $\begin{array}{l}\text { Group } 2 \\
(n=20)\end{array}$ & $\begin{array}{l}\text { Group } 3 \\
(n=21)\end{array}$ & $\mathbf{P}^{1}$ & Group/p \\
\hline Age (year) & $\begin{array}{l}28.05 \pm \\
5.38\end{array}$ & $\begin{array}{l}29.35 \pm \\
4.42\end{array}$ & $\begin{array}{l}30.33 \pm \\
4.60\end{array}$ & 0.32 & \\
\hline BMI $\left(\mathrm{kg} / \mathrm{m}^{2}\right)$ & $\begin{array}{l}24.15 \pm \\
3.19\end{array}$ & $\begin{array}{l}22.60 \pm \\
3.08\end{array}$ & $\begin{array}{l}24.38 \pm \\
3.34\end{array}$ & 0.16 & \\
\hline IOP $(\mathrm{mmHg})$ & $\begin{array}{l}16.07 \pm \\
2.92\end{array}$ & $\begin{array}{l}14.97 \pm \\
2.47\end{array}$ & $\begin{array}{l}14.47 \pm \\
2.76\end{array}$ & 0.030 & $\begin{array}{l}1-3 p= \\
0.02^{1}\end{array}$ \\
\hline \multirow[t]{2}{*}{$C / D$} & $0.15 \pm 0.06$ & $0.17 \pm 0.08$ & $0.23 \pm 0.1$ & $0.000 *$ & $\begin{array}{l}1-3 p= \\
0.000^{1}\end{array}$ \\
\hline & & & & & $\begin{array}{l}2-3 p= \\
0.003^{2}\end{array}$ \\
\hline СCT $(\mu \mathrm{m})$ & $\begin{array}{l}553.21 \pm \\
29.10\end{array}$ & $\begin{array}{l}554.16 \pm \\
30.88\end{array}$ & $\begin{array}{l}559.24 \pm \\
23.93\end{array}$ & 0.58 & \\
\hline Estrogen2 (pg/ml) & $\begin{array}{l}75.60 \pm \\
58.71\end{array}$ & & & & \\
\hline Testosterone (pg/ml) & $\begin{array}{l}16.35 \pm \\
13.33\end{array}$ & & & & \\
\hline $\begin{array}{l}\text { Testosterone usage time } \\
\text { (month) }\end{array}$ & $\begin{array}{l}29.66 \pm \\
9.80\end{array}$ & & & & \\
\hline
\end{tabular}

The means of the 9 total MT subfields, and IRL and ORL thickness of fovea are shown in Table 2. The thickness of fovea in men was significantly higher than Group $2(p=0.01)$. Para Sup and Para Inf thickness in FMT were significantly higher than Group $2(p=0.02, p=0.03)$. Peri Sup thickness in FMT was significantly higher than Group $3(p=0.01)$. Peri Nas thickness in FMT was significantly higher than Group $2(p=0.01)$. Peri Inf thickness in FMT was significantly higher than Group 2 and $3(p=0.03, p=$ 0.002). IRL of the fovea in men was significantly higher than Group $2(p=0.003)$. ORL thickness of fovea in FMT was significantly higher than Group $2(p=0.033)$. 
Table 2

Macular thickness in the macular region, and inner and outher thickness in the fovea and perifovea: comparison between all groups.

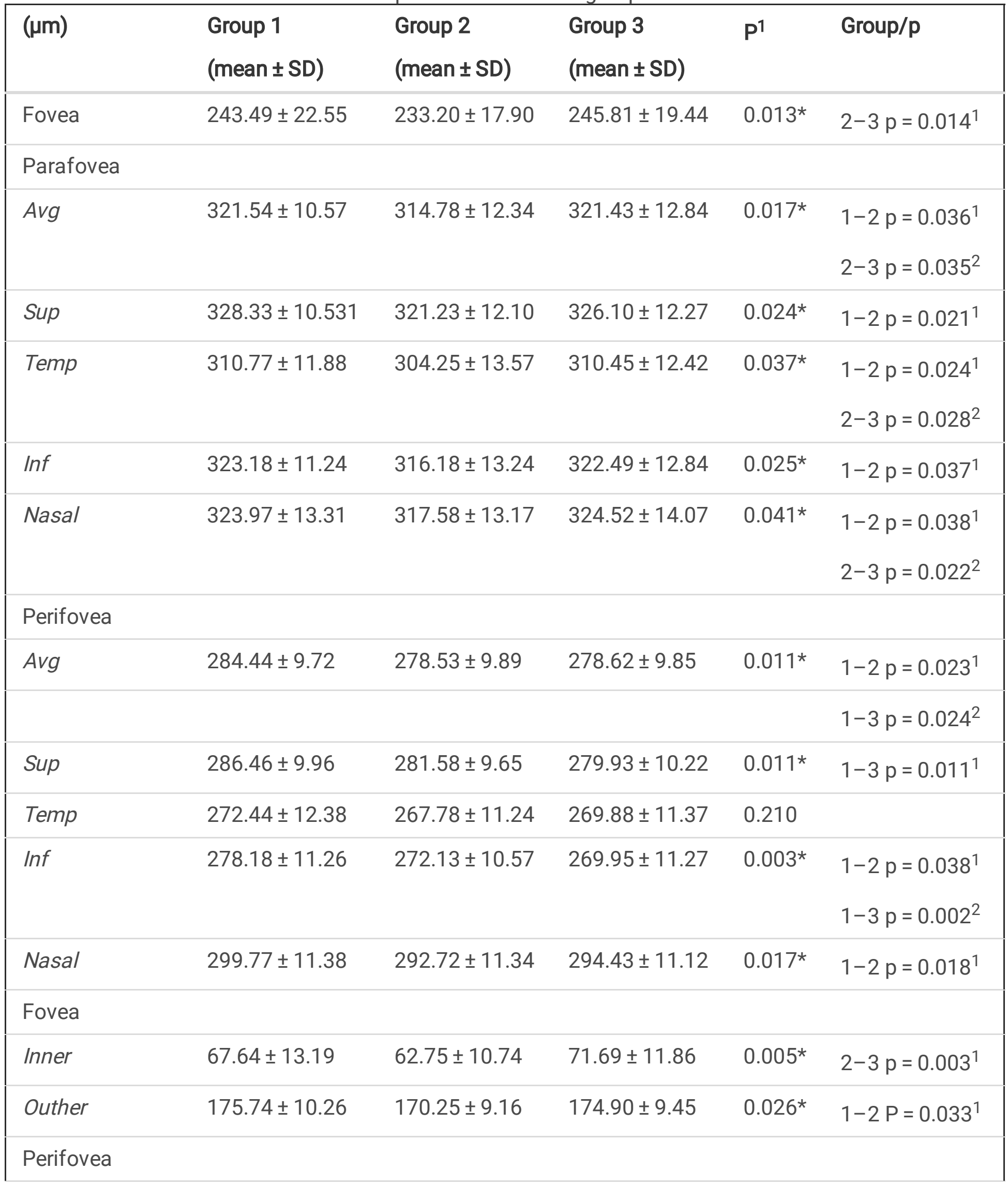




\begin{tabular}{|c|c|c|c|c|c|}
\hline$(\mu \mathrm{m})$ & $\begin{array}{l}\text { Group } 1 \\
\text { (mean } \pm \text { SD) }\end{array}$ & $\begin{array}{l}\text { Group } 2 \\
\text { (mean } \pm \text { SD) }\end{array}$ & $\begin{array}{l}\text { Group } 3 \\
\text { (mean } \pm \text { SD) }\end{array}$ & $P^{1}$ & Group/p \\
\hline Inner & $109.05 \pm 4.57$ & $105.97 \pm 5.26$ & $105.11 \pm 4.09$ & $0.001^{\star}$ & $\begin{array}{l}1-2 p=0.011^{1} \\
1-3 p=0.001^{2}\end{array}$ \\
\hline Outher & $175.74 \pm 6.43$ & $172.62 \pm 7.15$ & $173.33 \pm 6.56$ & 0.101 & \\
\hline \multicolumn{6}{|c|}{ Perifovea Sup } \\
\hline Inner & $108.95 \pm 3.88$ & $106.05 \pm 5.78$ & $104.98 \pm 4.52$ & $0.001^{\star}$ & $\begin{array}{l}1-2 p=0.032^{1} \\
1-3 p=0.000^{2}\end{array}$ \\
\hline Outher & $177.79 \pm 7.57$ & $175,53 \pm 7.24$ & $174.95 \pm 6.85$ & 0.182 & \\
\hline \multicolumn{6}{|c|}{ Perifovea Temp } \\
\hline Inner & $102.10 \pm 6.11$ & $98.53 \pm 5,94$ & $98.71 \pm 5.69$ & $0.012^{\star}$ & $\begin{array}{l}1-2 p=0.022^{1} \\
1-3 p=0.030^{2}\end{array}$ \\
\hline Outher & $171.00 \pm 8.29$ & $169.13 \pm 7.96$ & $171.10 \pm 7.47$ & 0.454 & \\
\hline \multicolumn{6}{|c|}{ Perifovea Inf } \\
\hline Inner & $107.11 \pm 6.40$ & $103.80 \pm 5.77$ & $101.83 \pm 4.84$ & $0.000 *$ & $\begin{array}{l}1-2 p=0.031^{1} \\
1-3 p=0.000^{2}\end{array}$ \\
\hline Outher & $171.69 \pm 6.33$ & $168.35 \pm 7.40$ & $168.22 \pm 7.11$ & $0.046^{\star}$ & $\begin{array}{l}1-2 p=0.035^{1} \\
1-3 p=0.028^{2}\end{array}$ \\
\hline \multicolumn{6}{|c|}{ Perifovea Nasal } \\
\hline Inner & $119.18 \pm 7.79$ & $115.58 \pm 6.94$ & $115.48 \pm 6.60$ & $0.035^{\star}$ & $\begin{array}{l}1-2 p=0.027^{1} \\
1-3 p=0.021^{2}\end{array}$ \\
\hline Outher & $182.18 \pm 8.11$ & $177.18 \pm 9.73$ & $178.83 \pm 7.39$ & $0.031^{*}$ & $1-2 p=0.026^{1}$ \\
\hline
\end{tabular}

The means of the IRL and ORL thickness of perifovea are shown in Table 2. The Avg, Temp, Sup, Inf thickness of IRL in perifovea in FMT were significantly higher than the Groups 2 and $3(p=0.012, p=$ $0.001, p=0.000)$. Nas ORL in perifovea in FMT was significantly higher than Group $2(p=0.026)$. 
The means of the RNLF and GCC values of all groups are shown in Table 3. The means of RNLF Sup in men were significantly higher than Groups 1 and $2(p=0.03, p=0.031)$. The means of RNLF Inf in FMT were significantly higher than Groups 2 and $3(p=0.039, p=0.032)$. The means of Avg, Inf of GCC in FMT were significantly higher than Group $2(p=0.02, p=0.005)$.

Table 3

RNLF and GCC thickness: comparison between all groups

\begin{tabular}{|c|c|c|c|c|c|}
\hline & $\begin{array}{l}\text { Group } 1 \\
\text { (mean } \pm \text { SD) }\end{array}$ & $\begin{array}{l}\text { Group } 2 \\
\text { (mean } \pm \text { SD) }\end{array}$ & $\begin{array}{l}\text { Group } 3 \\
\text { (mean } \pm \text { SD) }\end{array}$ & $P^{1}$ & Group/p \\
\hline \multicolumn{6}{|c|}{ RNFL $(\mu m)$} \\
\hline Avg & $109.54 \pm 5.70$ & $106.50 \pm 10.00$ & $107.40 \pm 8.75$ & 0.259 & \\
\hline Sup & $132.79 \pm 11.48$ & $132.88 \pm 15.75$ & $140.48 \pm 12.71$ & $0.014^{\star}$ & $\begin{array}{l}1-3 p=0.030^{1} \\
2-3 p=0.031^{2}\end{array}$ \\
\hline Temp & $83.03 \pm 12.06$ & $82.70 \pm 9.48$ & $80.50 \pm 8.74$ & 0.474 & \\
\hline Inf & $139.95 \pm 10.91$ & $131.75 \pm 15.91$ & $131.57 \pm 16.56$ & $0.018^{*}$ & $\begin{array}{l}1-2 p=0.039^{1} \\
1-3 p=0.032^{2}\end{array}$ \\
\hline Nasal & $82.05 \pm 11.33$ & $78.75 \pm 11.55$ & $77.33 \pm 9.58$ & 0.14 & \\
\hline \multicolumn{6}{|c|}{$\operatorname{GCC}(\mu m)$} \\
\hline Avg & $101.01 \pm 4.59$ & $97.60 \pm 6.47$ & $99.10 \pm 4.81$ & $0.026^{*}$ & $1-2 p=0.020^{1}$ \\
\hline Sup & $100.38 \pm 4.59$ & $98.00 \pm 6.30$ & $99,14 \pm 5.07$ & 0.150 & \\
\hline Inf & $101.85 \pm 6.22$ & $97.51 \pm 6.69$ & $99.06 \pm 5.06$ & $0.006^{*}$ & $1-2 p=0.005^{1}$ \\
\hline
\end{tabular}

The means of Colour Doppler USG in the ophthalmic artery (OA), central retinal artery (CRA), and posterior ciliary artery (CA) parameters are shown in Table 4.There was no difference between the groups in OA, CRA, and CA parameters. 
Table 4

Colour Doppler Ultrasonography in Ophthalmic Artery, Central Retinal Artery and Posterior Ciliary Artery parametres: comparison between all groups.

\begin{tabular}{|lllll|}
\hline & $\begin{array}{l}\text { Group 1 } \\
\text { (mean } \pm \text { SD) }\end{array}$ & $\begin{array}{l}\text { Group 2 } \\
\text { (mean } \pm \text { SD) }\end{array}$ & $\begin{array}{l}\text { Group 3 } \\
\text { (mean } \pm \text { SD) }\end{array}$ & P' \\
\hline Ophthalmic Artery & & & & \\
\hline$P S V$ & $30.72 \pm 6.51$ & $29.45 \pm 8.49$ & $31.95 \pm 7.69$ & 0.579 \\
\hline EDV & $8.16 \pm 2.39$ & $7.46 \pm 2.21$ & $7.45 \pm 2.99$ & 0.604 \\
\hline$P I$ & $1.47 \pm 0.38$ & $1.64 \pm 0.47$ & $1.73 \pm 0.46$ & 0.170 \\
\hline$R I$ & $0.75 \pm 0.14$ & $0.74 \pm 0.08$ & $0.77 \pm 0.06$ & 0.700 \\
\hline$S / D$ & $3.93 \pm 0.99$ & $3.97 \pm 0.88$ & $4.33 \pm 1.06$ & 0.365 \\
\hline Central Retinal Artery & & & & \\
\hline$P S V$ & $9.10 \pm 2.22$ & $11.06 \pm 2.52$ & $9.95 \pm 2.86$ & 0.058 \\
\hline EDV & $2.80 \pm 1.66$ & $3.01 \pm 1.18$ & $3.17 \pm 1.29$ & 0.621 \\
\hline$P I$ & $1.33 \pm 0.38$ & $1.40 \pm 0.31$ & $1.33 \pm 0.34$ & 0.785 \\
\hline$R I$ & $0.70 \pm 0.09$ & $0.72 \pm 0.07$ & $0.70 \pm 0.09$ & 0.636 \\
\hline$S / D$ & $3.44 \pm 0.88$ & $3.62 \pm 0.90$ & $3.29 \pm 0.81$ & 0.485 \\
\hline Posterior Ciliary Artery & & & & \\
\hline$P S V$ & $13.38 \pm 3.14$ & $14.31 \pm 5.19$ & $14.06 \pm 4.34$ & 0.781 \\
\hline EDV & $4.18 \pm 1.17$ & $5.35 \pm 2.21$ & $5.13 \pm 2.31$ & 0.145 \\
\hline$P I$ & $1.22 \pm 0.17$ & $1.13 \pm 0.29$ & $1.12 \pm 0.23$ & 0.352 \\
\hline$R I$ & $0.68 \pm 0.07$ & $0.63 \pm 0.07$ & $0.69 \pm 0.24$ & 0.309 \\
\hline$S / D$ & $3.11 \pm 0.50$ & $2.78 \pm 0.53$ & $2.92 \pm 0.55$ & 0.153 \\
\hline Peak systolic velocity (PSV), end diastolic volume (EDV),resistance index (RI), pulsatility index (PI), & \\
\hline systole/diastole ratio(S/D) & 1 & & & \\
\hline
\end{tabular}

In correlation test, $S / D$ ratio in $\mathrm{OA}(r=0.504, p=0.028)$ and peri Inf RNLF thickness $(r=0.485, p=0.035)$ were positively correlated with the serum levels of testosterone in FMT.

\section{Discussion}

In this study, the effects of testosterone on IOP, MT, RNLF, GCC, and ocular blood flow in FMT persons were compared with healthy women and men. In our study, we found that the use of testosterone 
increased IOP, MT, RNFL, and GCC thickness in transgender male individuals having female genetics. In addition, we found that the serum level of testosterone was positively correlated with Peri Inf thickness in macula and S/D ratio in OA in FMT.

In our study, no difference was found between men and women in terms of IOP values. The highest IOP was found in FMT individuals using testosterone, and this was statistically significant when compared with men. The effect of hormones, especially estrogen, on IOP has been shown in many studies [7, 22]. It has been stated that despite the effect of estrogen's lowering IOP, high testosterone levels can increase IOP and increase the risk of glaucoma $[23,24]$. Evidence that testosterone increases IOP has also been reported in patients with PCOS [18]. These studies are consistent with our work. In addition to studies reporting lower IOP in women compared to men, there are also studies stating that gender is not effective $[25,26]$. In our study, the mean IOP of women was found to be higher than men, but this difference was not statistically significant. Endogenous high testosterone may not have the same effects as exogenous testosterone [27]. However, this situation may explain the statistical significance between FMTs, which are genetically females, and males, and can be interpreted as exogenous testosterone IOP in the female sex.

Although we found lower mean IOP in men in our study, we found that the cup/disc (C/D)ratio of men were significantly higher than FMT and women. In the literature, there are studies stating that the C/D ratio is higher in men than in women [28]. A positive correlation between disk size and the C/D ratio has been reported [29]. However, fundus photography of the cases was not performed in our study and this may be a limiting point.

In our study, the foveal thickness was greatest in the male gender. Many studies in the literature also support this finding [30]. However, the striking point is that the mean of MT measurements in FMT was significantly increased in the Para Inf, Para Sup, Peri Nas, and Peri Inf area compared to women. In addition, the mean of MT measurements in FMT has significantly increased in the Peri Inf area compared to men and it was correlated with serum testosterone levels. In a study conducted in patients with PCOS, it was stated that testosterone increased MT, but this increase may be caused by metabolic syndrome accompanying PCOS leading to Muller cell defect and macular edema [31].

Inner and outer layer thickness measurements of the macula were made to determine which layer was affected by the testosterone. There were statistically significant differences between the groups in terms of IRL and ORN. Foveal measurement in $1 \mathrm{~mm}$ area with FD-OCT device covers $0.35 \mathrm{~mm}$ foveola area due to retinal anatomy and this area consists of rod and cone cells. Although there was no difference in the ORL between men and women in the fovea region, the IRL was significantly higher in men than women. However, this difference was not present in the perifoveal area. In FTM, there was a significant increase in $\mathrm{ORL}$ in the foveal area compared to women. For these reasons, we think that testosterone may have a trophic effect on rod and cone cells. At the same time, the increase in MT especially in the para and perifoveal area and in the IRL of the macula in FMT cases suggests that testosterone may also be effective in the inner nuclear layer with an increase in the GCC layer. 
Another important point of our study is the positive effects of testosterone on RNLF and GCC layers. In FMT, Inf RNLF was significantly higher than women and men. We found that the means of Avg GCC and Sup GCC were significantly higher in FMT than in women. The neuroprotective effect of testosterone on the nervous system has been demonstrated by regeneration and improvement in neurons and glia [19, 20]. Besides, increased RNLF thickness has been reported in studies conducted with patients with PCOS. It is stated that this trophic effect is partly due to androgen and partly to nerve growth factor (NGF) detected in cases with PCOS $[17,18,31]$. Our patients had normal ovarian size and appearance and did not show PCOS findings. Therefore, we think that the increase in thickness in RNLF and GCC is due to the trophic and neuroprotective effects of testosterone.

In our study, we did not observe any difference in ocular blood flow between the three groups in CRA, OA and posterior CA. However, in correlation test, S/D ratio in OA was positively correlated with the serum levels of testosterone in FMT. There are limited studies on the effects of hormones on ocular hemodynamics and gender differences. A study investigating retrobulbar blood flow in men and women under 40 years of age indicated that ocular blood flow velocity was higher in the OA and lower in the short posterior CA in men compared to women [32]. Studies on ocular blood flow and hormones mostly focused on estrogen. Many studies have reported that estrogen decreases vascular resistance in the retinal vessel and OA and increases flow velocity $[7,9]$. However, while testosterone increases RI in the central retinal artery and ophthalmic artery, it decreases the flow velocity in the central retinal artery. Testosterone works as an antagonist despite the positive effect of estrogen [13]. In another study conducted on patients with PCOS, it was reported that androgens increased ocular blood flow however they increased vascular resistance only in the OA[33]. In our study, there was no difference between the groups in CRA, OA and CA parameters. However, the absence of our patients in surgical menopause may have hidden the effects of testosterone on vessels. In addition, Doppler blood flow studies have some limitations. Doppler results depend on the experience of the ultrasonographer, which makes it difficult to generalize and standardize the results. Nevertheless, as studies on hormones and ocular blood flow increase, our knowledge on this subject will increase.

According to the Androgen Exess Society (AES), hyperandrogenism is indispensable in the diagnosis of PCOS. Clinical or laboratory hyperandrogenism occurs in PCOS. However, the dose of testosterone taken in FMT cases is a supraphysiological dose. Therefore the, FMT group creates valuable data to understand the effects of testosterone on the eye. As far as we can find from the literature, ours is the first study investigating the ocular findings of FMT individuals. The strengths of this study are its prospective nature, the examination of multiple parameters, and compliance with exclusion criteria in selecting control groups. The major limitation of the study was small sample size.

In conclusion, in our study comparing FMT individuals with normal controls, we found that testosterone caused an increase in IOP and an increase in the macula, RNLF, and GCC thicknesses. The effects of testosterone on macular thickness increase were prominent in the inner layer. In addition, serum testosterone level was positively correlated with S/D ratio in the OA. In the light of these findings, we 
conclude that testosterone has trophic and neuroprotective effects and also has effects on ocular blood flow.

\section{Declarations}

Funding: The authors did not receive support from any organization for the submitted work.

Conflicts of interest: The authors have no conflicts of interest to declare that are relevant to the content of this article.

Availability of data and material: Applicable

Code availability: Not applicable

Authors' contributions: All authors contributed to the study conception and design. Material preparation, data collection and analysis were performed by Oksan Alpogan, Emin Erhan Donmez, Ayşe Özlem Balık, Fisun Vural and Gizem Kaplan. The first draft of the manuscript was written by Oksan Alpogan and all authors commented on previous versions of the manuscript. All authors read and approved the final manuscript.

Ethics approval: This study was performed in line with the principles of the Declaration of Helsinki. Approval was granted by Research Protocol and Ethics Committee of Haydarpasa Numune Training and Research Hospital (HNEAH-KAEK 2020/212).

Consent to participate: Informed consent was obtained from all individual participants included in the study.

Consent for publication: Patients signed informed consent regarding publishing their data and photographs.

Acknowledgments: The authors thank Prof. Dr. Sarper Karakucuk for language editing of the manuscript.

\section{References}

1. Rosner W, Hankinson SE, Sluss PM, Vesper HW, Wierman ME (2013) Challenges to the measurement of estradiol: an Endocrine Society position statement. J Clin Endocrinol Metab 98(4): 1376-1387. DOI: $10.1210 / j \mathrm{jc} .2012-3780$

2. Simpson ER (2003) Sources of estrogen and their importance. J Steroid Biochem Mol Biol 86(35):225-30. DOI: 10.1016/s0960-0760(03)00360-1

3. Gupta PD, Johar K, Nagpal K, Vasavada AR (2005) Sex hormone receptors in the human eye. Surv Ophthalmol 50(3):274-84. DOI: 10.1016/j.survophthal.2005.02.005

4. Wickham LA, Gao J, Toda I, Rocha EM, Ono M, Sullivan DA (2000) Identification of androgen, estrogen and progesterone receptor mRNAs in the eye. Acta Ophthalmol Scand 78(2):146-53. 
DOI: 10.1034/j.1600-0420.2000.078002146.x

5. Guarnieri P, Guarnieri R, Cascio C, Pavasant P, Piccoli F, Papadopoulos V (1994)

Neurosteroidogenesis in rat retinas. J Neurochem 63(1): 86-96. DOI: 10.1046/j.14714159.1994.63010086.x

6. Cascio C, Russo D, Drago G, Galizzi G, Passantino R, Guarneri R, et al (2007) 17beta-estradiol synthesis in the adult male rat retina. Exp Eye Res 85(1): 166-72. DOI: 10.1016/j.exer.2007.02.008

7. Altintaş O, Caglar Y, Yüksel N, Demirci A, Karabaş L (2004) The effects of menopause and hormone replacement therapy on quality and quantity of tear, intraocular pressure and ocular blood flow. Ophthalmologica 218(2): 120-9. DOI: 10.1159/000076148

8. Harris A, Harris M, Biller J, Garzozi H, Zarfty D, Ciulla TA, et al (2000) Aging affects the retrobulber circulation differently in women and men. Arch Ophthalmol 118(8): 1076-80.

DOI: 10.1001/archopht.118.8.1076

9. Deschênes MC, Descovich D, Moreau M, Granger L, Kuchel GA, Mikkola TS, et al (2010) Postmenopausal hormone therapy increases retinal blood flow and protects the retinal nerve fiber layer. Invest Ophthalmol Vis Sci 51(5): 2587-600. DOI: 10.1167/iovs.09-3710

10. Nakazawa T, Takahashi H, Shimura M (2006) Estrogen has a neuroprotective effect on axotomized RGCs through ERK signal transduction pathway. Brain Res 1093(1): 141-915.

DOI: 10.1016/j.brainres.2006.03.084

11. Kumar DM, Perez E, Cai ZY, Aoun P, Brun-Zinkernagel AM, Covey DF, et al (2005) Role of nonfeminizing estrogen analogues in neuroprotection of rat retinal gangion cells against glutamateinduced cytotoxicity. Free Radic Biol Med 38(9): 1152-63. DOI: 10.1016/j.freeradbiomed.2004.12.007

12. Ozawa GY, Bearse MA, Harrison WW, Bronson-Castain K, Schneck ME, Barez S, et al (2014) Differences in neuroretinal function between adult males and females. Optom Vis Sci 91: 602-607. DOI: 10.1097/OPX.0000000000000255

13. Toker E, Yenice O, Akpinar I, Aribal E, Kazokoglu H (2003) The influence of sex hormones on ocular blood flow in women. Acta Ophthalmol Scand 81(6): 617-24. DOI: 10.1111/j.13953907.2003.00160.x

14. Littleton-Kearney M, Hurn PD. Testosterone as a modulator of vascular behavior (2004) Biol Res Nurs 5(4): 276-85. DOI: 10.1177/1099800403262927

15. Horwitz KB \& Horwitz LD (1982) Canine vascular tissues are targets for androgens, oestrogens, progestins and glucocorticoids. J Clin Invest 69: 750 - 758. DOI: 10.1172/jci110513

16. Tostes RC, Fortes ZB, Callera GE, Montezano AC, Touyz RM, Webb RC, et al (2008) Endothelin, sex and hypertension. Clin Sci (Lond) 114(2): 85-97. DOI: 10.1042/CS20070169

17. Dissen GA, Garcia-Rudaz C, Paredes A, Mayer C, Mayerhofer A, Ojeda SR (2009) Excessive ovarian production of nerve growth factor facilitates development of cystic ovarian morphology in mice and is a feature of polycystic ovarian syndrome in humans. Endocrinology 150(6): 2906-2914. DOI: 10.1210/en.2008-1575 
18. Demir M, Guven D, Koc A, Ozdemir S, Can E (2013) Retinal Nerve Fiber Layer Thickness in Women with Polycystic Ovary Syndrome. J Ophthalmol 2013: 752186. DOI: 10.1155/2013/752186

19. Białek M, Zaremba P, Borowicz KK, Czuczwar SJ (2004) Neuroprotective role of testosterone in the nervous system. Pol J of Pharmacol 56(5): 509-518.

20. Byers JS, Huguenard AL, Kuruppu D, Liu N-K, Xu X-M, Sengelaub DR (2012) Neuroprotective effects of testosterone on motoneuron and muscle morphology following spinal cord injury. J Comp Neurol 520(12): 2683-2696. DOI: 10.1002/cne.23066

21. Perrin JS, Hervé PY, Leonard G, Perron M, Pike GB, Pitiot A, et al (2008) Growth of white matter in the adolescent brain: role of testosterone and androgen receptor. J Neurosci 28(38): 9519-24.

DOI: 10.1523/JNEUROSCI.1212-08.2008

22. Toker E, Yenice O, Temel A (2003) Influence of serum levels of sex hormones on intraocular pressure in menopausal women. J Glaucoma 12(5): 436-40. DOI: 10.1097/00061198-200310000-00007

23. Pasquale LR, Kang JH (2011) Female reproductive factors and primary open-angle glaucoma in the Nurses' Health Study. Eye (Lond) 25(5): 633-41. DOI: 10.1038/eye.2011.34

24. Karaca Adiyeke S, Karaca I, Yildirim S, Adiyeke M, Uyar I, Ture G (2017) Anterior Segment Findings in Women with Polycystic Ovary Syndrome. Turk J Ophthalmol 47(1): 24-7. DOI: 10.4274/tjo.73659

25. Cohen E, Kramer M, Shochat T, Goldberg E, Krause I (2017) Relationship between hematocrit levels and intraocular pressure in men and women: A population-based cross-sectional study. Medicine (Baltimore) 96(41): e8290. DOI: 10.1097/MD.0000000000008290

26. Hashemi H, Kashi AH, Fotouhi A, Mohammad K (2005) Distribution of intraocular pressure in healthy Iranian individuals: the Tehran Eye Study. Br J Ophthalmol 89(6): 652-7.

DOI: $10.1136 /$ bjo.2004.058057

27. Holmegard HN, Nordestgaard BG, Schnohr P, Tybjaerg-Hansen A, Benn M (2014) Endogenous sex hormones and risk of venous thromboembolism in women and men. J Thromb Haemost 12: 297305. DOI: $10.1111 /$ jth. 12484

28. Varma R, Tielsch JM, Quigley HA, Hilton SC, Katz J, Spaeth GL, et al (1994) Race-, age-, gender-, and refractive error-related differences in the normal optic disc. Arch Ophthalmol 112(8): 1068-76.

DOI: 10.1001/archopht.1994.01090200074026

29. Crowston JG, Hopley CR, Healey PR, Lee A, Mitchell P; Blue Mountains Eye Study (2004) The effect of optic disc diameter on vertical cup to disc ratio percentiles in a population based cohort: the Blue Mountains Eye Study. Br J Ophthalmol 88(6): 766-70. DOI: 10.1136/bjo.2003.028548

30. Adhi M, Aziz S, Muhammad K, Adhi MI (2012) Macular thickness by age and gender in healthy eyes using spectral domain optical coherence tomography. PLoS One 7(5): e37638.

DOI: 10.1371/journal.pone.0037638

31. de Souza-Júnior JE, Garcia CA, Soares EM, Maranhão TM, Lemos TM, Azevedo GD (2015) Polycystic ovary syndrome: aggressive or protective factor for the retina? Evaluation of macular thickness and retinal nerve fiber layers using high-definition optical coherence tomography. J Ophthalmol 2015: 193078. DOI: 10.1155/2015/193078 
32. Ustymowicz A, Mariak Z, Weigele J, Lyson T, Kochanowicz J, Krejza J (2005) Normal reference intervals and ranges of side-to-side and day-to-day variability of ocular blood flow Doppler parameters. Ultrasound Med Biol 31: 895-903. DOI: 10.1016/j.ultrasmedbio.2005.03.013

33. Örnek N, İnal M, Tulmaç ÖB, Özcan-Dağ Z, Örnek K (2015) Ocular blood flow in polycystic ovary syndrome. J Obstet Gynaecol Res 41(7): 1080-6. DOI: 10.1111/jog.12673

\section{Figures}



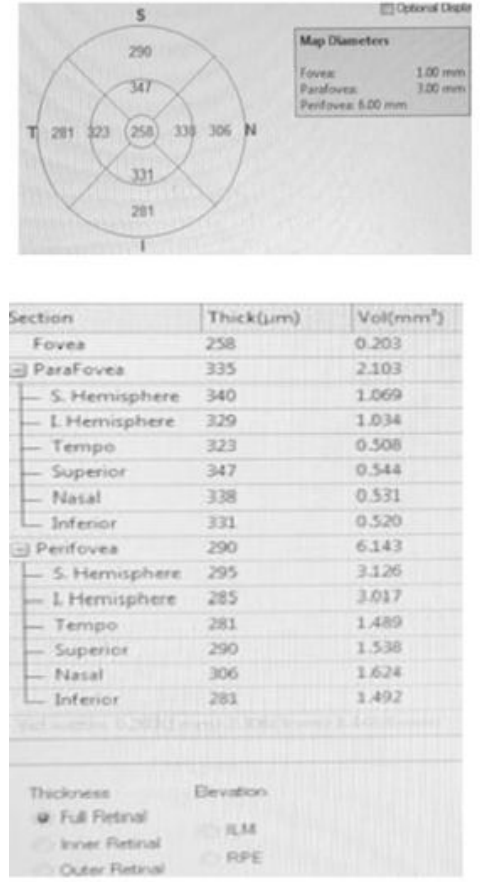
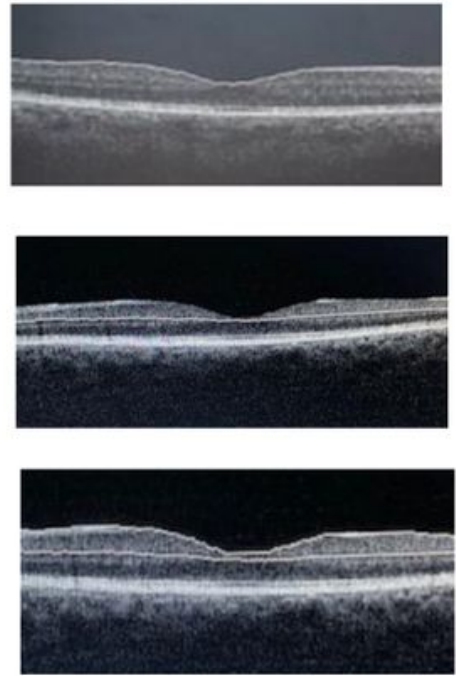

(a)

$\underline{\text { RNFL and GCC thicknesses }}$
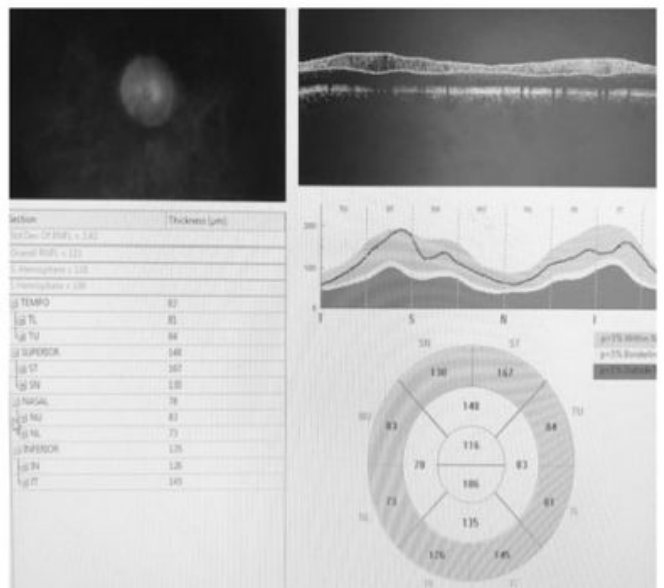

(b)

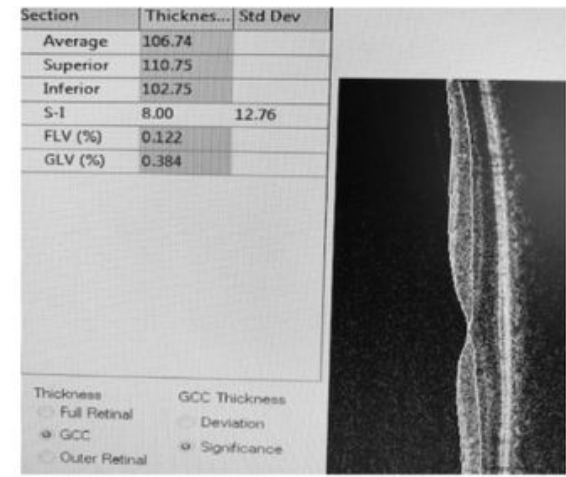

(c)

Figure1

\section{Figure 1}

(a) "Measuring total macular thickness (upper), outher macular thickness (middle) and inner macular thickness (bottom) with producing a map with 09 subfields of sectoral thickness in three concentric circles, as defined by ETDRS. (b) "Measuring RNFL thickness using 13 concentric ring scans 1.3 to 4.9 $\mathrm{mm}$ in diameter centered on the optic disc. (c) "Measuring GCC using the scan protocol GCC". 